\title{
Study of Swadhishthana Chakra and Hypogastric Plexus in View of Reproductive Activity
}

\author{
Neha Balakrishna Pitla ${ }^{1}$, Pradnya Ravindra Deshpande ${ }^{2}$ \\ ${ }^{1}$ PG Scholar, Department of RachanaSharir, Government Ayurved College, Nanded \\ ${ }^{2}$ Assistant Professor, Department of RachanaSharir, Government Ayurved College, Nanded
}

\begin{abstract}
Principles of Ayurveda favour the well-being of each individual to lead a healthy life physically, mentally and socially. It emphasizes the importance of preventive medicine along with curative procedures to give a holistic approach towards a healthy living. The Chakras play an important role to maintain the spiritual, mental, emotional and physical health of the body. The Chakras are energy centres within the human body that help to regulate all its processes, from organ function to the immune system and emotions. There are six primary chakras Muladhara Chakra, Swadhishthana Chakra,Manipura Chakra, Vishuddha Chakra, Anahata Chakra and Ajna Chakra which are located along a central vertical axis at the front of the body. The Chakras are considered loci of life energy or Prana, which is thought to flow among them along pathways called Nadis. The Chakra is used to mean several different things in Sanskrit sources, of which it can be denoted to different nerve plexuses within the body. Reproduction is the biological process by which new individual organisms "off-spring” are produced from their parents. Reproduction is a fundamental feature of all known life. Hypogastric plexus gives out branches to the male and female reproductive organs, whereas Swadhishthana Chakra plays an important role in the act of procreation. This article will emphasize on the similarities between Swadhishthana Chakra and Hypogastric plexus and the role of both in reproduction.
\end{abstract}

Keywords: Swadhishthana Chakra, Hypogastric plexus, Reproduction

\section{Introduction}

Ayurveda means the science of life. Harmony of body, mind and soul is achieved by the traditional system of medicine Ayurveda. In Ayurveda, Sharirterm is affiliated to the one which undergoes anabolism and catabolism at every moment. Ayurveda assumed that Sharir is composed of Panchamahabhuta and atma ${ }^{[1]}$. Panchamahabhuta i.e Aakash, Vayu, Agni, Aap and Pruthvietc are considered to be basic elements of body. Sharirwhich is Panchabhautic is further divided as Ang-Pratyangafor detail study ${ }^{[2]}$. One concept of Ang- Pratyanga is related to specific areas of body which are known as force centers and described in Patanjalyogdarshanas Chakras. The word Chakra in Sanskrit is for "wheel". The word is derived from kriyategatirerena", one which has the action of movement ${ }^{[3]}$. The Chakras are said to be force centers or whorls of energy permeating from a point on the physical body, the layers of the subtle bodies in an ever increasing fan-shaped formation. Rotating vortices of subtle matter, they are considered the focal points for the reception and transmission of energies. Each is different in form, makeup, colour and frequency. There are said to be six major Chakras, 21-minor Chakras and over 700 mini Chakras on the body that relate to acupuncture and major reflex points. The structure of a Chakra differs from Chakra to Chakra. Its general shape resemble to an inverted ice-cream cone, with the narrow end attached to the physical body. The Chakras vitalize and harmonize the physical, etheric and emotional bodies. They facilitate the development of selfconsciousness. The Chakras can become imbalanced in different ways by becoming congested, overstimulated or uncoordinated. From lowest to highest, there are six primary Chakras Muladhara Chakra, Swadhishthana Chakra, Manipura Chakra, Anahata Chakra, VishuddhaChakra and Ajna Chakra ${ }^{[4]}$. Each Chakra is the sum total of various physical, emotional, mental and spiritual elements. Each
Chakra can be correlated to a neurological plexus. Swadhishthana Chakra can be correlated to the Hypogastric plexus. Swadhishthana Chakra is the Chakra of creativity. The meaning of the word Swadhishthanais "one's own base".Swadhishthana Chakra is the "dwelling place of self". The Plexus in latin means 'Braid', which is a branching network of vessels or nerves. The vessels may be blood vessels or lymphatic vessels. There are different types of nervous plexus, venous plexus, cardiac plexus, coeliac plexus and choroid plexus ${ }^{[5]}$.

\section{Discussion}

The systems of the body participate in maintaining homeostasis, that is, the relative constancy of the internal environment despite external environment changes. There are ten major organ systems in the human body which can be stated as follows Integumentary system, Muscular system, Skeletal system, Lymphatic system , Digestive system, Endocrine system, Circulatory System, Respiratory system, Urinary System, Nervous System ${ }^{[6]}$. Each one plays a vital role in maintaining equilibrium within the body. All the systems work in tandem to maintain homeostasis. The proper functioning of the body requires all systems to work together and in proper condition. Many diseases can affect the various organs and organ systems of the body. The reproductive system helps in maintaining the homeostasis in male and female by regulating the vagina $\mathrm{pH}$ and the overall temperature of testis. Reproduction is important for the survival of all living things. Without the mechanism of reproduction, life would come to an end. For this purpose, functions of male and female reproductive organs should be maintained.

\section{Literature on Swadhishthana Chakra ${ }^{[7]}$}

Volume 6 Issue 1, January 2017

www.ijsr.net

Licensed Under Creative Commons Attribution CC BY 


\section{International Journal of Science and Research (IJSR) \\ ISSN (Online): 2319-7064}

Index Copernicus Value (2015): 78.96 | Impact Factor (2015): 6.391

Literary meaning of Swadhishthana is one's own base. The location of Chakra is said to be "Saushumana Madhya GhatitamDhvajamul" i.e. it is located on the spinal cord of the vertebral column just above the pubic bone and below the navel and encompasses the genital region. The colour of the Chakra is white. Associated element of the Chakra is water.Sensory organ is Tongue and Gyanendriya is Taste. The bearer of the Chakra is Crocodile. Presiding God is said to be Brahma. Granthisthana is said to be Varuna. Symbol of the Chakra is said to be a crescent moon with 6 divisionsi.eDalas. Swadhishthana Chakra is associated with Prana, Samana and ApanVayu.ApanVayu has an influence over the pelvic region. Swadhishthana Chakra is associated with the genital organs of male and female especially testes and ovaries. Swadhishthana Chakra is the Chakra of creativity. This Chakra corresponds to the Hypogastric plexus.

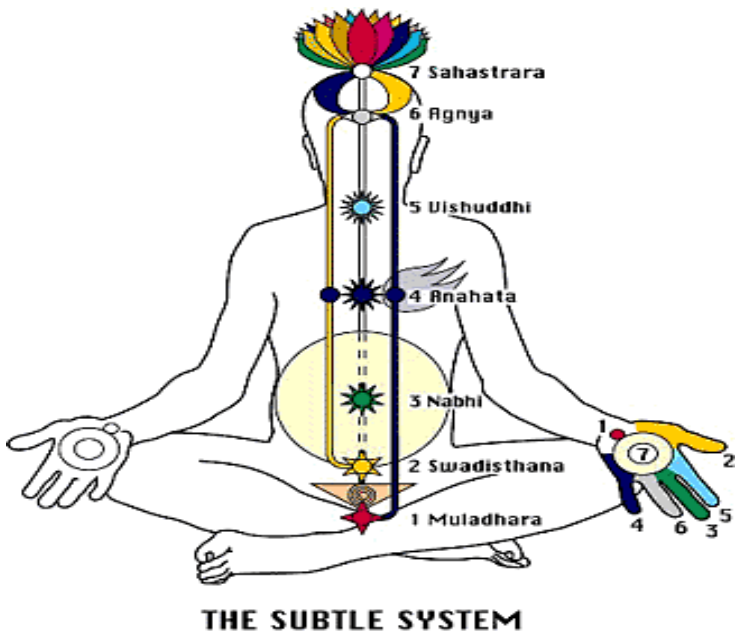

Figure 1: Location of Swadhishthana Chakra

\section{Literature on Hypogastric Plexus ${ }^{[8]}$}

Hypogastric plexus is divided into the superior Hypogastric plexus and Inferior Hypogastric plexus. The superior hypogastric plexus is anterior to the aortic bifurcation, the left common iliac vein, median sacral vessels, fifth lumbar vertebral body and sacral promontory and between the common iliac arteries. Often termed the presacral nerve, it is seldom a single nerve and is prelumbar rather than presacral. It lies in extraperitoneal connective tissue; the parietal peritoneum can easily be stripped off its anterior aspect. It varies in breadth and condensation of its constituent nerves and is often a little to one side of the midline; the attachment of the sigmoid colon, containing superior rectal vessels, is to the left of the lower part of the plexus. Scattered neurons occur in it. The plexus is formed by branches from the aortic plexus and third and fourth lumbar splanchnic nerves. It divides into right and left hypogastric nerves which descend to the two Inferior Hypogastric plexuses. The superior plexus supplies branches to the ureteric, testicular, ovarian and common iliac plexuses. In addition to sympathetic fibres, it may also contain parasympathetic fibres which ascend from the inferior Hypogastric plexus; but these fibres usually ascend to the left of the superior Hypogastric plexus and across the sigmoid branches of left colic vessels. These parasympathetic fibres are distributed partly along the inferior mesenteric arterial branches and also as independent retroperitoneal nerves, to supply the left part of the transverse colon, left colic flexure, descending and sigmoid colon.

The inferior hypogastric plexus is in the extraperitoneal connective tissue. In males it is lateral to: the rectum, seminal vesicle, prostate and the posterior part of the urinary bladder; in females each plexus is lateral to: the rectum, uterine cervix, vaginal fornix and the posterior part of the urinary bladder, extending into the broad uterine ligament. Lateral to it are the internal iliac vessels and their branches and tributaries, the levatorani, coccygeus and obturatorinternus. Posterior are the sacral and coccygeal plexuses and above are the superior vesical and obliterated umbilical arteries. The plexuses contain numerous small ganglia. Each is formed by a hypogastric nerve, conveying most of the sympathetic fibres of the plexus, the remaining few arriving via branches from the ganglia. Parasympathetic fibres are derived from pelvic splanchnic nerves. Preganglionic efferent sympathetic fibres originate in the lower three thoracic and upper two lumbar spinal segments, some relaying in ganglia of the lumbar and sacral parts of the sympathetic trunk, others synapsing in the lower part of the aortic plexus and in the superior and inferior hypogastric plexuses. Preganglionic parasympathetic fibres originate in the second to fourth sacral spinal segments, reach the plexus in the pelvic splanchnic nerves and synapse in it or walls of Viscera supplied by its branches. Numerous branches are distributed to the pelvic and some abdominal viscera, either directly or along their arteries. Parasympathetic fibres ascend in the Hypogastric plexuses or as separate filaments to reach the inferior mesenteric plexus by way of the aortic plexus. By this route the descending and parts of the sigmoid colon receive parasympathetic innervation.

The Hypogastric plexus gives out innervation to the following plexuses below

The ureteric plexus receives in its intermediate part from the superior hypogastric plexus and hypogastric nerve and in its lower part from the inferior hypogastric plexus and hypogastricnerve.This supply influences the inherent motility of the ureter.

The testicular plexus accompanies the gonadal artery to the testis. Its upper part receives branches from the renal and aortic plexuses. Distally it is reinforced from the superior hypogastric and inferior hypogastric plexuses. It's rami pass to the epididymis and ductus deferens.

The ovarian plexus accompanies the ovarian artery to the ovary and uterine tube. The upper part is formed by branches from the renal and aortic plexuses; it's lower part is reinforced from the superior and inferior hypogastric plexuses. The nerves in the testicular and ovarian plexuses contain efferent and afferent sympathetic fibres; the efferent are vasomotor and derived from the tenth and eleventh thoracic spinal segments; the parasympathetic fibres, from the inferior hypogastric plexuses are probably vasodilator.

The middle rectal plexus formed by fibres from the upper part of the inferior hypogastric plexus to the rectum passing directly or along the middle rectal artery, connects above 


\section{International Journal of Science and Research (IJSR) \\ ISSN (Online): 2319-7064}

Index Copernicus Value (2015): 78.96 | Impact Factor (2015): 6.391

with the superior rectal plexus and extends below to the internal anal sphincter.

The vesical plexus from the anterior part of the inferior hypogastricplexus, comprises many filaments which pass along vesical arteries to the bladder. Branches supply the seminal vesicles and deferent ducts. The prostatic plexus, continued from the lower part of the inferior hypogastric plexus, is composed of large nerves entering the base and sides of the prostate and contains neurons.

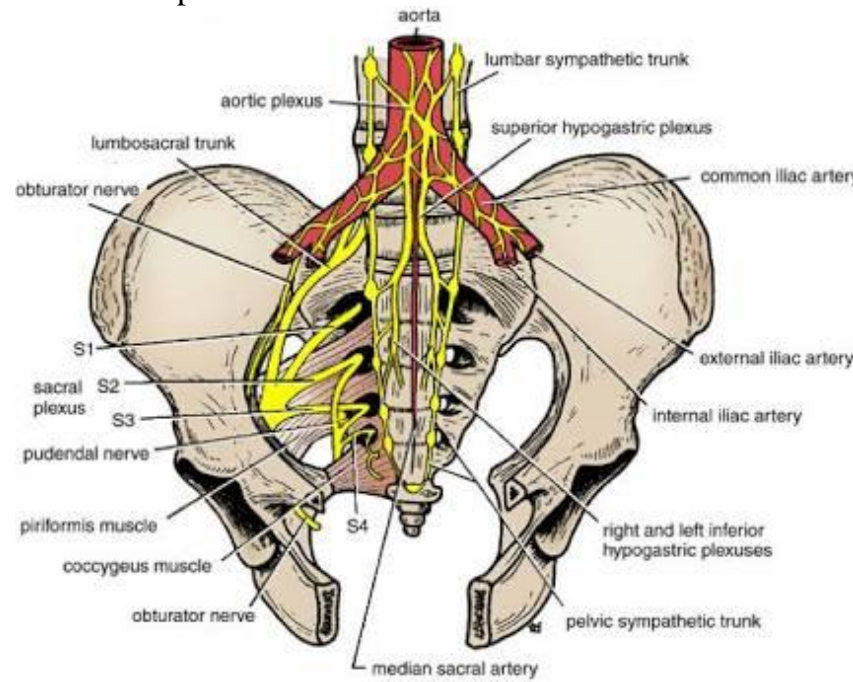

Figure 2: Location of Hypogastric Plexus

\section{Swadhishthana Chakra, Hypogastric Plexus and Reproduction}

The reproductive system is a collection of internal and external organs in both males and females that work together for procreating. It has a vital role in survival of the species. The male reproductive system consists of two major parts testis and the penis. The female reproductive system is divided into external and internal genitalia. The internal organs which are important for reproduction are ovaries, fallopian tubes, uterus and vagina. Infertility is the leading issue in today's generation. Infertility occurs when there is a pathological cause in the male and female reproductive system. There is an association of function of SwadhishthanaChakra and hypogastric plexus and the act of procreation.

If we focus on the location of Swadhishthana Chakra, it occupies the genital region. It is associated with the testis and ovaries, they produce the hormones testosterone or estrogen which influence sexual behaviour and has a very strong influence upon our moods and emotions. They are stored in areas where genetic information lies dormant, in the same way that samskaras lie dormant within Swadhishthana. This Chakra is connected with the sense of taste and reproduction therefore it is known as the Chakra of creativity. A balanced Chakra leads to feelings of wellness, abundance pleasure and joy. When this Chakra is out of balance a person may experience emotional instability, fear of change, sexual dysfunction, depression or addictions. Swadhishthana Chakra is also responsible for purification of all bodily fluids through the kidneys, bladder and lymph system has it is associated with the kidneys and entire urinary system.
One of the plexus related to the region of Swadhishthana Chakrais the hypogastric plexus which gives out branches to the male and female reproductive organs, when damage to the plexus occurs especially inferior hypogastric plexus in male causes urinary retention, erectile impotence, ejaculatory dysfunction, reduced intestinal motility which leads to constipation and reduced functioning of the internal anal canal. In female damage to this plexus causes difficulty in micturition, defecation, sexual dysfunction and inhibition of uterine contraction.

The anatomical positions are given in both acupoint and anatomical terms and represent the point on the physical body that is usually the center of the influence of the Chakra. Although an exact point is given for each Chakra. There is an area of influence around each major Chakra point.From textual references we can state some similarities between SwadhishthanaChakra and hypogastricplexus, the location of both Swadhishthanachakra and hypogastric plexus is said to be in the pelvic region. The Swadhishthana Chakra has 6Dalaswhich can be compared to the 6 branches of the hypogastricplexus on the basis of the numeration and structure of the Chakra. The 6 branches of the hypogastric plexus are ureteric plexus, testicular plexus, ovarian plexus, middle rectal plexus, vesical plexus and prostatic plexus. The malfunctioning of both can cause manifestations of the male and female genital organs.

Malfunctioning of the Swadhishthana Chakra can cause disturbances in relationships, represses emotions, emotional instability and issues related to fertility. To avoid these conditions various Asanas have been described in the yog texts. Regular practise of Bhujangasana ${ }^{[9], S h a l a b h a s a n a,}$ Dhanurasana, Mrigasana, Chakrasana, Surya namaskara, Setu asana According to the HathayogPradipika two mudras Vajroli mudra and Amroli Mudra are specially assigned to the Swadhishthana Chakra for its activation ${ }^{[9]}$.

Related to the location of basic elements (vata-pitta-kapha) of body, area of swadhishthanachakra is the main site of apanavayu. Whatever may be the organs present there, are completely under the influence of apan-vayukarma Shukranishkramana (semen ejaculation, transport etc), aartawanishkramana ( menstruation, ovum transport etc) and fetal expulsion are the functions of reproductive organs at region of swadhishthana chakra governed by apanavayu.

\section{Conclusion}

Each major Chakragoverns specific part of the body which in turnis associated with an autonomic nerve plexus, an endocrine gland, an organ and a meridian. The link between the external Chakra and the internal organ is the Nadis, the invisible web of energy that penetrates and permeates the physical frame.SwadhishthanaChakra,hypogastric plexus and Apanvayu have an influence on the organs in the pelvic region.These are different entities which play an important role in reproduction. Swadhishthana Chakra may be correlated to the hypogastric plexus on the basis of its location, its numeration and its traumatic effect. The 6 Dalasmay be correlated to the branches of the hypogastric plexus. The function of the Swadhishthana Chakra is said to be in procreation i.e reproduction. Similarly hypogastric 


\section{International Journal of Science and Research (IJSR) \\ ISSN (Online): 2319-7064}

Index Copernicus Value (2015): 78.96 | Impact Factor (2015): 6.391

plexus has a major role in reproduction. Trauma to the hypogastric plexus may be a reason for infertility in male and female. So it is important to keep Swadhishthana Chakra activated by practising the AsanasandPranayamto maintain and protect the reproductive system and its function.

\section{References}

[1] Chakrapanidutt, Ayurveddipika, CharakSamhita, Vyakhyasanvilita, $4^{\text {th }}$, Chaukhambha Sanskrit sansthan, Varanasi, Page no- 787

[2] KavirajAmbikaduttshashtri, SushrutaSamhita, Ayurvedtatvasandipika, Vaigyanikvimarsh, Purvardh, Reprint 2007, Chaukhambha Sanskrit Sansthan, Varanasi, Page no -56

[3] Review Study Of Anahata Chakra w.s.r to Cardiac Plexus, Deepa, BhatnagarVikash, LahangeSandeep M, ISSN: 2320 5091, IAMJ: Volume 4; issue 03; March2016

[4] John R. Cross, Healing with the Chakra Energy System, 2006, North Atlantic Books, Page no- 17-23

[5] TortoraDerrickson, Principles of Anatomy and Physiology, $11^{\text {th }}$ Edition, John wiley and sons Inc, Page no 4-11

[6] TortoraDerrickson, Principles of Anatomy and Physiology, $11^{\text {th }}$ Edition, John wiley and sons Inc, Page no 448,530

[7] Dr.Tarachandsharma, AyurvediyaSharirRachana, NathPusthakBhandhar, Page No- 370-371

[8] Gray's Anatomy, 37 ${ }^{\text {th }}$ Edition 1989, Churchill livingstone medical division of longman group UK limited, Page no -1165-1167

[9] GherandSamhita, ChamanlalGautam, Sanskrit sansthan, Yamuna Printing Press Mathura, 1975, Page no- 72-73

[10] Hathyogpradipika,Swatmaramyogindravirchta, Sanskrit tika, 1985-2041,Srivyankateshwarmudranalay Mumbai, Page no- 117- 125

\section{Authors Profile}

Dr. Neha Balakrishna Pitla is P.G Scholar, Government Ayurved college, Nanded

9. Dr. Pradnya Ravindra Deshpande is Assistant Professor, Government Ayurved College, Nanded 